\title{
PRIMARY LINGUAL TUBERCULOSIS PRESENTING AS HEMIMACROGLOSSIA: A CASE REPORT
}

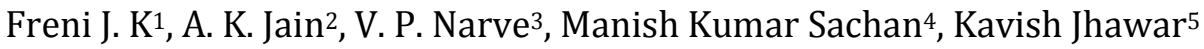

\section{HOW TO CITE THIS ARTICLE:}

Freni J. K, A. K. Jain, V. P. Narve, Manish Kumar Sachan, Kavish Jhawar. "Primary Lingual Tuberculosis Presenting as Hemimacroglossia: A Case Report". Journal of Evolution of Medical and Dental Sciences 2014; Vol. 3, Issue 28, July 14; Page: 7674-7677, DOI: 10.14260/jemds/2014/2954

ABSTRACT: Tuberculosis is a chronic granulomatous disease which can affect any part of the body. Both primary and secondary tuberculosis can occur in the oral cavity, of which primary is a rare condition with the tongue being the most commonly affected site. We report a case of primary tuberculosis of tongue in a 46 year old male patient who presented with hemimacroglossia. Tuberculosis was not suspected clinically and there was no other focus elsewhere in the body. FNAC was attempted but was inconclusive. Diagnosis was made after histopathological examination.

KEYWORDS: Histopathology, tongue, tuberculosis.

INTRODUCTION: Tuberculosis is a chronic granulomatous disease that can affect various systems of the body. It is caused mainly by Mycobacterium tuberculosis, Mycobacterium bovis, and other atypical mycobacterial species. ${ }^{1}$ Pulmonary tuberculosis is the most common primary form of disease. However it can occur in lymph nodes, meninges, kidneys, bones, skin and oral cavity.

Secondary tuberculosis occurs from a healed primary focus or due to endogenous spread of infection. Both primary and secondary tuberculosis can occur in the oral cavity which accounts for 0.2 to $1.5 \%$ of all cases of extrapulmonary tuberculosis. Primary tuberculosis of the oral cavity is exceedingly rare with the tongue being the most commonly affected site.,2,3

CASE HISTORY: A 46 year old male patient from Gwalior (MP) presented in the ENT OPD with complaints of burning sensation of tongue for 8months, progressively increasing swelling of the tongue for 6 months, difficulty in chewing and swallowing for 2 months. No documented history of fever, cough, weight loss or any chronic illness. Patient was a smoker for the past $25 y$ years. No history of contact with tuberculosis.

On examination, patient was moderately built and nourished. There was no lymphadenopathy or organomegaly. Examination of oral cavity revealed a diffuse, firm swelling of $6 \times 3 \mathrm{cms}$ over the left side of the anterior $2 / 3^{\text {rd }}$ of the tongue involving dorsum, left lateral border and ventral surface, with smooth surface and ill-defined margins, no fluctuation. The lesion apparently looked like hemimacroglossia.

Tongue movements was not restricted. Systemic examination did not reveal any abnormal findings. Complete blood counts, ESR were within normal limits. ELISA test for HIV was non-reactive. Chest X ray was normal. USG abdomen was normal. FNAC from the swelling was inconclusive. Hemiglossectomy was done and tissue was sent for histopathological examination. Microscopic examination revealed mild hyperkeratosis and acanthotic epithelium, sub epithelium showed plenty of granulomas with Langhan's type of giant cells surrounded by inflammatory cells.

Thus, final diagnosis of primary tuberculosis of tongue was made, and patient was referred to Respiratory Medicine and Category I anti TB therapy was started. 


\section{CASE REPORT}

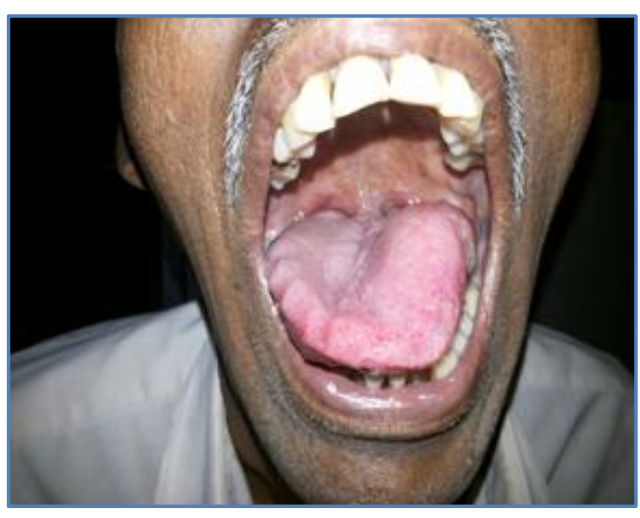

Pre 0p

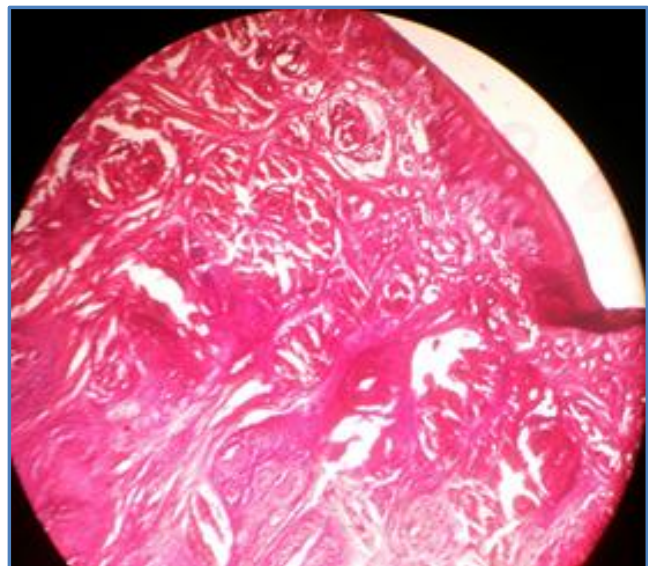

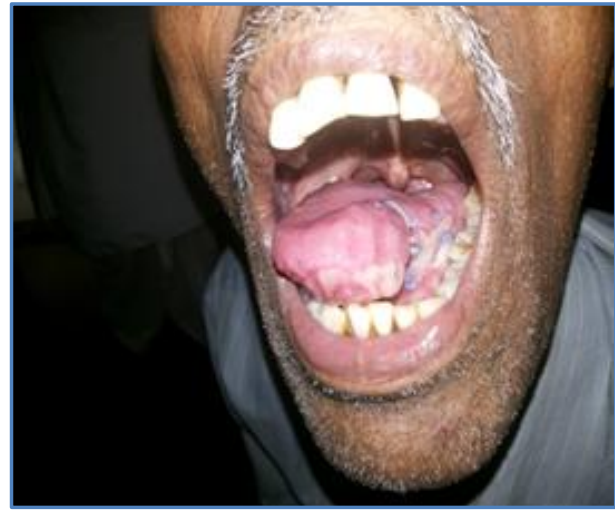

Post Op

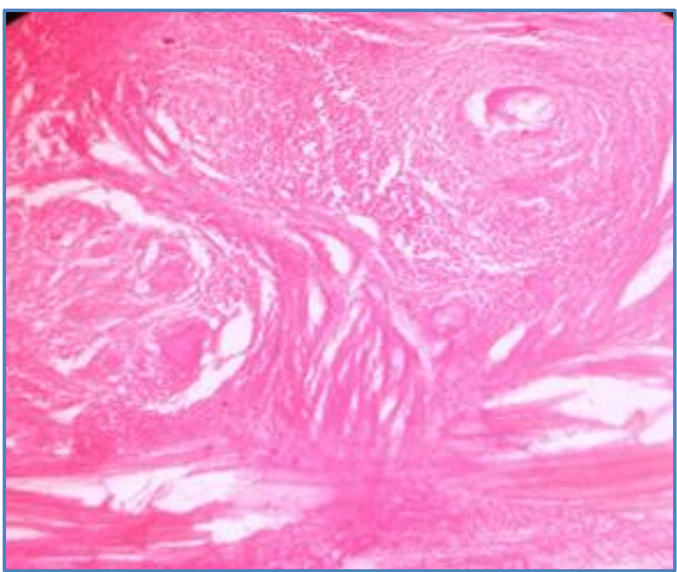

HPE showing Tuberculous granuloma with periphery showing multinucleated giant cells

DISCUSSION: Oral cavity constitutes $0.2 \%$ to $1.5 \%$ of all extrapulmonary tuberculosis sites. ${ }^{4}$ The oral sites most commonly involved are tongue, palate, tonsil, pharynx and buccal mucosa. The cleansing effect of saliva, relative paucity of lymphoid tissue in the tongue, and the antagonist oral commensals are all reasons for decreased virulence of TB in oral cavity. Tongue is a muscular organ with good vascularity and activity further contributing to the defense against tuberculosis 5 .Morgagni first described the case of lingual tuberculosis in $1761 .^{6}$ Lingual tuberculosis is more frequently diagnosed in immunocompromised patients, males and smokers.

Tuberculosis in oral cavity is usually secondary to pulmonary involvement. Primary tuberculosis of oral cavity usually occurs following a breach in the oral mucosa as a result of chronic tobacco use, traumatizing dentures, tooth extractions or poor oral hygiene. Hence, role of trauma cannot be underestimated, as the stratified squamous epithelium of oral cavity normally resists direct penetration of tubercle bacilli. In secondary tuberculosis, the oral manifestations are accompanied by lesion in lung, lymph nodes, or any other site of the body. This can be detected by the usual clinical history and systemic examination. Primary oral tuberculosis may thus present as a diagnostic challenge to the clinician. ${ }^{7}$ 
"Macroglossia" in tuberculosis is extremely rare, which is defined as an enlarged tongue. Enlargement of half of the tongue is termed as "hemimacroglossia" as was observed in the present case. Macroglossia is a clinical presentation which has an extensive list of possible causes such as haemangioma, lymphangioma, Down syndrome, Beckwith Wiedemann syndrome, hypothyroidism, acromegaly, neurofibromatosis, tuberculosis, diabetes mellitus, glossitis, polymyositis and idiopathic. Severe macroglossia can lead to cosmetic and functional disturbances as in speaking, eating, swallowing, and sleeping. Aird has described five pathological types of lesion due to tuberculosis. ${ }^{8}$

1) Tubercular ulcer: It is painful and usually develops as a small tubercle which later on softens to form an ulcer. Typically the ulcer is shallow, ovoid, with undermined margins and lined with pale granulation tissue.

2) Tuberculoma: Originates as a lump anywhere in the tongue resembling lingual gumma. The lump in due course of time softens to form an ulcer.

3) Tuberculous fissure: They usually occur on the side of tongue, can be appreciated only by separating their edges.

4) Tubercle papilloma: An overgrowth of the margins of tubercular fissures.

5) Tubercular cold abscess: Due to breakdown of a tuberculoma.

Clinically the diagnosis of oral tuberculosis is not possible and sometimes imaging investigations are not helpful. Especially in our case, the rarer presentation of lingual tuberculosis in the form of swelling of the tongue in the form of hemimacroglossia, led us to clinical misconception. Finally the diagnosis was established only after excisional biopsy (hemiglossectomy in our case) and histopathological examination. In histopathology, macrophages, lymphocytes, and fibroblasts are among the cells that aggregate to form granuloma with lymphocytes surrounding the infected macrophages, also features necrosis in the centre casseous necrosis. Multinucleated Langhan's giant cells are often present around the periphery of the granuloma.

Tuberculosis of the tongue is to be differentiated from non-specific ulcerative lesions, traumatic lesions, and malignant lesions primary or metastatic. No matter whether primary or secondary oral tuberculosis, an early suspicion and timely intervention can lead to favorable outcome in such cases.

\section{REFERENCES:}

1. Prabhu SR, Wilson DF, Daftry DK, Johnson NW. "Oral diseases in the tropics." Oxford university press; 1993.

2. Gupta PP, Fotedar S, Agarwal D, Sanswal P. "Primary tubercular glossitis in an immuno competent patient". Hong kong Med J 2009; 13 (4): 330-331.

3. Sareen D, Sethi A, Agarwal AK. "Primary tuberculosis of the tongue: a rare nodular presentation". British Dental J 2006; 200 (6): 321-322.

4. EM Iype, K Ramdas, M Pandey et al, "Primary tuberculosis of the tongue: report of three cases", British Journal of Oral and Maxillofacial surgery, 2001; Vol.39(5): 402-403.

5. V Ramesh, "Tuberculoma of the tongue presenting as macroglossia" 1997; Cutis, Vol.60, no.4, pp. 201-202. 


\section{CASE REPORT}

6. SK Vishwakarma, S Jain, M Gupta, "Primary lingual tuberculosis presenting as cold abscess tongue: a case report", Indian Journal of Otolaryngology and Head and Neck Surgery, 2006; Vol. 58(1), pp 87-88.

7. V Kumar, AP Singh, R Meher, A Raj, "Primary Tuberculosis of oral cavity: a rare entity revisited", Indian Journal of Paediatrics, Vol. 78. no.3, pp.354-356, 2011.

8. SPS Yadav, Arpit Agarwal, JS Gulia, Sunita Singh, Arsh Gupta, Vineet Panchal, "Tuberculoma of the tongue presenting as Hemimacroglossia." Case Reports in Medicine, Vol 2012, article ID 548350, 3 pages http://dx.doi.org/10.1155/2012/543850.

\section{AUTHORS:}

1. Freni J. K.

2. A. K. Jain

3. V.P. Narve

4. Manish Kumar Sachan

5. Kavish Jhawar

\section{PARTICULARS OF CONTRIBUTORS:}

1. $2^{\text {nd }}$ Year Post Graduate Student, Department of Otorhinolaryngology, Gajra Raja Medical College, Gwalior, M. P.

2. Professor and HOD, Department of Otorhinolaryngology, Gajra Raja Medical College, Gwalior, M. P.

3. Associate Professor, Department of Otorhinolaryngology, Gajra Raja Medical College, Gwalior, M. P.

4. $3^{\text {rd }}$ Year Post Graduate Student, Department of Otorhinolaryngology, Gajra Raja Medical College. Gwalior. M. P.
5. $\quad 2^{\text {nd }}$ year Post Graduate Student, Department of Otorhinolaryngology, Gajra Raja Medical College, Gwalior, M. P.

\section{NAME ADDRESS EMAIL ID OF THE CORRESPONDING AUTHOR:}

Dr. A. K. Jain,

Professor and HOD,

Department of Otorhinolaryngology,

Ravi Aakriti Bina Complex,

Flat No. G1 and G2,

Gwalior, M. P.

Email: entjainak@hotmail.com

Date of Submission: 22/06/2014.

Date of Peer Review: 23/06/2014.

Date of Acceptance: 02/07/2014.

Date of Publishing: 07/07/2014. 